\title{
Nonelective cardiac surgery in the elderly: Is it justified?
}

\author{
Ravi K. Ghanta, MD, Prem S. Shekar, MD, Siobhan McGurk, BS, Donna M. Rosborough, RN, MS, \\ and Sary F. Aranki, MD
}

Objective: Elderly patients might be denied nonelective cardiac surgery because of the perception of poor outcomes and an unacceptable quality of life. In this study we evaluate long-term survival and quality of life in these patients.

\begin{abstract}
Methods: From 1994 to 1999, 262 consecutive patients older than 80 years underwent urgent $(\mathrm{n}=223)$ or emergent $(n=39)$ cardiac surgery. Of these patients, $160(61 \%)$ underwent coronary artery bypass grafting, $64(24 \%)$ underwent coronary artery bypass grafting plus valve surgery, $17(7 \%)$ underwent valve surgery, and 21 (8\%) underwent aortic surgery. Kaplan-Meier survival analysis and quality-of-life assessment were performed, and result were compared with age-adjusted population data. Risk factors for mortality were determined by using Cox regression. The utility of Society of Thoracic Surgeons and EuroSCORE risk scoring were assessed by using area under receiver operating curves.
\end{abstract}

Results: Early mortality was $11 \%(n=29)$ overall, $7 \%(n=16)$ in urgent cases, and 33\% $(n=13)$ in emergent cases. Five-year survival was 50\% $(n=132)$ overall, $53 \%(n=105)$ in urgent cases, and $36 \%(n=18)$ in emergent cases. There was no difference in 10-year survival between patients undergoing urgent surgical intervention and age-adjusted population data. Among survivors, quality-of-life measures were equivalent to those of the general elderly population. Risk factors for early mortality were age, emergent procedure, aortic procedure, bypass time, and postoperative complication (renal failure, myocardial infarction, cerebrovascular accident, pneumonia, and reoperation for bleeding). Risk factors for late mortality were peripheral vascular disease, emergent procedure, bypass time, and new renal failure. The EuroSCORE and Society of Thoracic Surgeons risk scores were equivalent but only moderately predictive of mortality.

Conclusions: Long-term survival and quality of life after nonelective cardiac surgery can equal that of the general elderly population. Age alone should not disqualify a patient for urgent or emergent cardiac surgery. (J Thorac Cardiovasc Surg 2010;140:103-9)

Supplemental material is available online.

Eighteen million persons are currently older than 75 years in the United States, and the number is expected to increase significantly over the next decade. ${ }^{1}$ Similar trends are occurring worldwide. $^{2}$ Cardiovascular disease remains the leading cause of morbidity and mortality in the elderly population. ${ }^{3}$ As the elderly population increases, cardiac surgery in octogenarian and nonagenarian patients is becoming increasingly common. ${ }^{4-6}$ However, elderly patients are less likely to be referred for elective cardiac surgery than younger

\footnotetext{
From the Division of Cardiac Surgery, Brigham and Women's Hospital, Harvard Medical School, Boston, Mass.

Supported by Brigham and Women's Hospital, Division of Cardiac Surgery.

Disclosures: None.

Received for publication July 9, 2009; revisions received Sept 16, 2009; accepted for publication Oct 3, 2009; available ahead of print Dec 14, 2009.

Address for reprints: Sary F. Aranki, MD, Division of Cardiac Surgery, Brigham and Women's Hospital, 75 Francis St, Boston, MA 02115 (E-mail: saranki@partners. org).

0022-5223/\$36.00

Crown Copyright (c) 2010 Published by Elsevier Inc. on behalf of The American Association for Thoracic Surgery

doi:10.1016/j.jtcvs.2009.10.001
}

patients. Many elderly patients view cardiac surgery as a risky proposition with little potential gain. Similarly, referring physicians also perceive poor outcomes and poor postoperative quality of life (QoL). ${ }^{7-9}$ For these reasons, elderly patients are more likely to present with unstable symptoms than younger patients, forcing consideration for urgent or emergent cardiac surgery. ${ }^{10}$ Several studies have demonstrated encouraging survival and QoL in elderly patients undergoing cardiac surgery but note that nonelective surgery is associated with 2 to 3 times greater risk. ${ }^{4,10-13}$

No prior study has evaluated long-term survival and QoL outcomes of elderly patients undergoing urgent or emergent cardiac surgery, and few data exist to guide clinical decision making for this patient population. The goal of this study is to evaluate the long-term survival and QoL for nonelective cardiac surgery in our octogenarian and nonagenarian patients. We compare these outcomes with age-adjusted population data. We also identify risk factors for early and late mortality and evaluate the utility of existing clinical predictive algorithms for this patient population.

\section{MATERIALS AND METHODS Patients \\ All patients 80 years of age or older who underwent nonelective cardiac surgery between January 1994 and December 1999 at Brigham and}




$$
\begin{aligned}
& \text { Abbreviations and Acronyms } \\
& \begin{aligned}
\text { AUROC } & =\text { area under the receiver operating curve } \\
\text { CABG } & =\text { coronary artery bypass grafting } \\
\text { CVA } & =\text { cerebrovascular accident } \\
\text { LOS } & =\text { length of stay } \\
\text { MI } & =\text { myocardial infarction } \\
\text { QoL } & =\text { quality of life } \\
\text { SF-12 } & \text { Medical Outcomes Study Short Form } \\
& 12 \\
\text { STS } & \text { Society of Thoracic Surgeons }
\end{aligned}
\end{aligned}
$$

Women's Hospital were identified. Nonelective surgery was defined as an urgent or emergent operation, as defined by the Society of Thoracic Surgeons, required for acute myocardial infarction (MI), unstable angina, critical coronary anatomy, cardiogenic shock, or aortic rupture or dissection. During this 5-year period, 262 consecutive patients were identified, of whom $223(80 \%)$ underwent urgent surgery and $39(20 \%)$ underwent emergent surgery. Patients' preoperative, operative, and postoperative variables were retrieved from the prospective Brigham Cardiac Surgery Database. Procedures were divided into coronary artery bypass grafting (CABG) alone, valve surgery with or without $\mathrm{CABG}$, and aortic surgery.

\section{Outcomes}

We evaluated the frequency of postoperative complications, length of stay (LOS), discharge disposition, early mortality, long-term survival, and long-term QoL. In all patients the postoperative course was followed, and intubation time and intensive care unit and hospital LOS and patient disposition were determined. Complications, such as death, cerebrovascular accident (CVA), pneumonia, new-onset atrial fibrillation, postoperative MI, reoperation for bleeding, and new-onset renal failure were identified. Early mortality was defined as death within 30 days of the operation or at any point while still in the hospital. CVA included strokes, transient ischemic attacks, and coma. New-onset renal failure was defined as a creatinine value of greater than $2.0 \mathrm{mg} / \mathrm{dL}$ with no history of preoperative renal failure. Pneumonia was identified in patients with positive bacterial sputum cultures or radiographic findings consistent with pulmonary infection. Postoperative MI was defined as the presence of at least 2 of the following: prolonged typical chest pain not relieved by nitrates, enzyme level increase, new wall motion abnormalities, and/or ST-segment or Q-wave electrocardiographic changes in 2 or more contiguous leads.

The vital status of all discharged patients was determined from medical records, a query of the Social Security Death Index, and/or communication with the patient's family or physician before August 2004. Survivors were then sent the Medical Outcomes Study Short Form 12 (SF-12) Health Survey, version 2, to evaluate QoL. ${ }^{14,15}$ The deadline for questionnaire return was March 2005. Long-term mortality through June 2008 was ascertained by means of a subsequent query of the Social Security Death Index and medical records.

\footnotetext{
Analysis and Statistical Methods

Statistical analyses were performed with SPSS 13.0 software (SPSS, Inc, Chicago, Ill), and a $P$ value of less than .05 was considered statistically significant. Evaluation of dichotomous variables was done with the Fisher's exact test. One-way analyses of variance were used to evaluate continuous variables. Survival curves were calculated by using the Kaplan-Meier method. ${ }^{16}$ Observed postoperative survival was compared with predicted survival of a similarly aged cohort from United States census data. ${ }^{17} \mathrm{~A}$ univariate followed by multivariate Cox proportional hazards regression from
}

preoperative, operative, and postoperative variables was performed to identify risk factors for late mortality. For early/operative mortality, only a univariate Cox proportional hazards regression was performed because there were too few mortalities to perform a multivariate model. The predicted operative mortality was calculated by using the Society of Thoracic Surgeons (STS) and the logistic European system for cardiac risk assessment (EuroSCORE) algorithms to evaluate the utility of existing clinical risk stratification protocols. ${ }^{18,19}$ The STS- and EuroSCORE-predicted operative mortality was then compared with the observed mortality. Receiver operating curves were determined, and the area under the receiver operating curve (AUROC) was used to assess the accuracy of the score in predicting mortality. ${ }^{20} \mathrm{QoL}$ data were compared with normative data for patients 75 years or older and patients with cardiac disease. ${ }^{14}$

\section{RESULTS \\ Patient Demographics}

Patient characteristics and comorbidities are summarized in Table 1. The mean age of patients at the time of surgical intervention was $83 \pm 3$ years, with a range of 80 to 93 years. There were 8 nonagenarians overall, with 4 undergoing urgent operations and 4 undergoing emergent operations. Preoperatively, $52 \%$ of patients demonstrated New York Heart Association Class III or IV heart failure. The most frequent preoperative comorbidities were hypertension $(74 \%)$, diabetes $(25 \%)$, renal failure $(16 \%)$, and history of CVA $(12 \%)$. Only 1 patient with preoperative renal failure was hemodialysis dependent. CABG alone was performed in $61 \%$ of patients, representing the most common surgical procedure. Valve surgery with or without CABG was performed in $31 \%$ of patients. Aortic surgery was performed in $8 \%$ of patients, including 5 patients with acute type A aortic dissection and 1 patient with a type B aortic dissection. Fourteen patients had an ascending aortic aneurysm with either possible rupture or concomitant ischemia and valve dysfunction requiring urgent or emergent repair. One patient had a ruptured descending thoracic aneurysm. Aortic surgery was more common in emergent cases. The most common indication for urgent surgery was unstable angina requiring intravenous nitroglycerin $(29 \%)$. The most common indication for emergent surgery was evolving MI $(41 \%)$. All procedures were performed with cardiopulmonary bypass. Thirty-one $(12 \%)$ patients had undergone previous cardiac operations.

\section{Postoperative Complications and Early Mortality}

Postoperative morbidity, mortality, and LOS are summarized in Table 2 . Early mortality was $11 \%$ overall, $7 \%$ in urgent cases, and $33 \%$ in emergent cases. The surgical procedures and cause of death in the emergent cases are listed in Table E1. The most frequent causes of death in this group were CVA, multisystem organ failure, and cardiac arrest. Overall, the most frequent postoperative complication was atrial fibrillation ( $48 \%$ of patients) followed by pneumonia $(28 \%)$, new-onset renal failure $(7.3 \%)$, reoperation for bleeding (7.6\%), and CVA (5.7\%). The median hospital LOS was 9 days, with a median intensive care unit LOS of 3 
TABLE 1. Patient preoperative and surgical characteristics

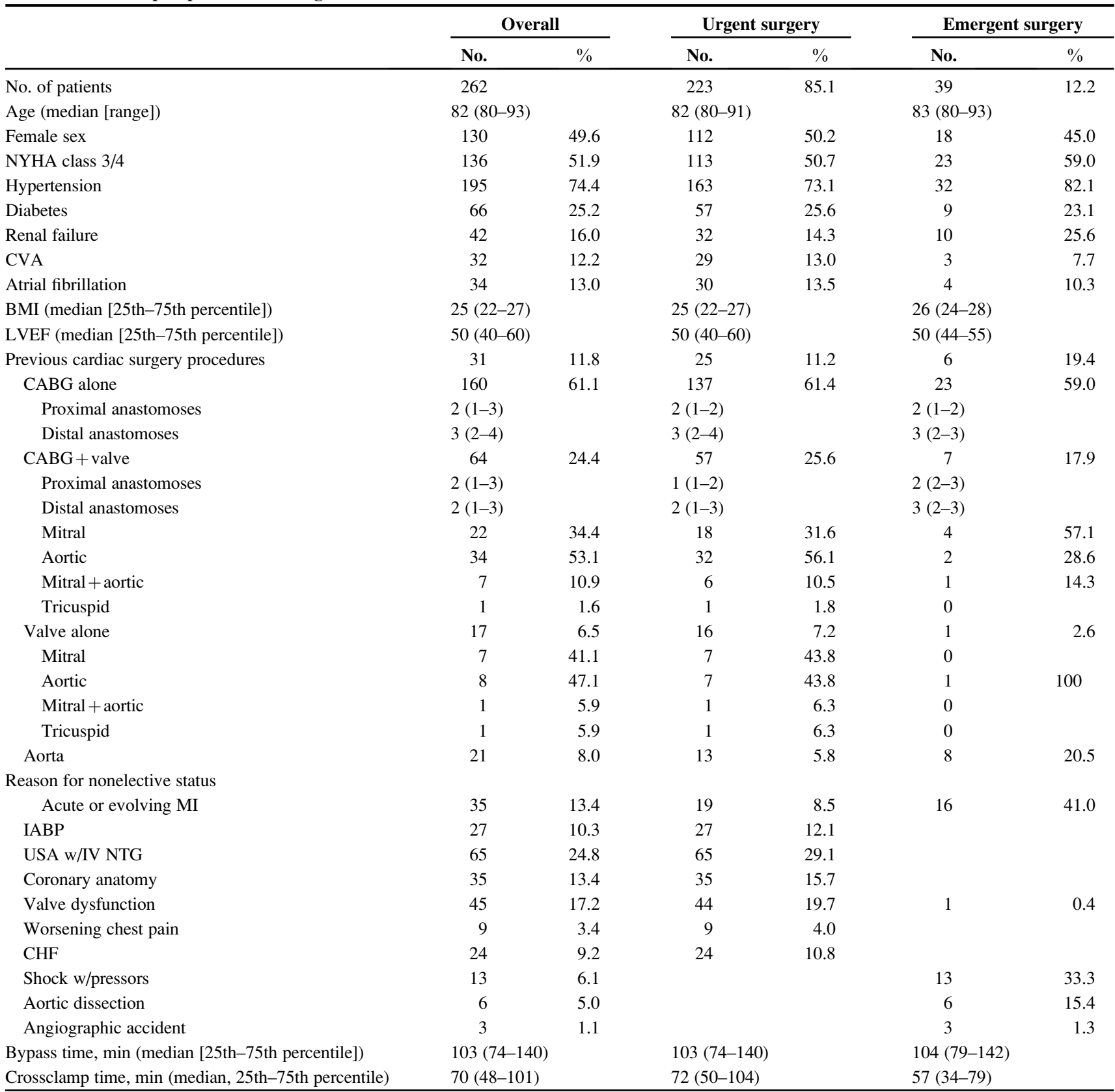

Number of proximal and distal anastomoses indicates median and 25th and 75th percentiles. NYHA, New York Heart Association; $C V A$, cerebrovascular accident; $B M I$, body mass index; $L V E F$, left ventricular ejection fraction; $C A B G$, coronary artery bypass grafting; $M I$, myocardial infarction; IABP, intra-aortic balloon pump; $U S A$ w/IV NTG, unstable angina with intravenous nitroglycerin; $C H F$, congestive heart failure.

days. Most patients $(68 \%)$ were discharged to a rehabilitation facility.

\section{Long-Term Survival}

Kaplan-Meier survival curves are presented in Figure 1, which demonstrates survival in the urgent and emergent groups compared with the expected survival for an agematched cohort from US census data. For urgent cardiac surgery 1-, 5-, and 10-year survival was $81.6 \%, 52.9 \%$, and
$30.7 \%$, respectively. For emergent cardiac surgery, 1-, 5-, and 10 -year survival was $48.7 \%, 35.9 \%$, and $15.4 \%$, respectively. For the age-matched cohort, 1-, 5-, and 10-year expected survival from census data was $92.4 \%, 62.9 \%$, and $34.8 \%$, respectively. There was no significant difference in 10-year survival between the general elderly population and patients requiring urgent cardiac surgery $(P=$ .188). Patients who required emergent surgery, however, had decreased 10 -year survival $(P<.01)$. Figure E1 
TABLE 2. Postoperative course, morbidity, and mortality

\begin{tabular}{|c|c|c|c|c|c|c|}
\hline & \multicolumn{2}{|c|}{ Overall } & \multicolumn{2}{|c|}{ Urgent surgery } & \multicolumn{2}{|c|}{ Emergent surgery } \\
\hline & No. & $\%$ & No. & $\%$ & No. & $\%$ \\
\hline No. of patients & 262 & & 223 & 85.1 & 39 & 12.2 \\
\hline Intubation time, $\mathrm{h}$ (median [25th-75th percentile) & $16.0(12-30)$ & & $16.0(12-25)$ & & $22.0(18-47)$ & \\
\hline ICU LOS, d (median, 25th-75th percentile) & $3(2-4)$ & & $3(2-4)$ & & $3(2-5)$ & \\
\hline Hospital LOS, d (median, 25th-75th percentile) & $9(7-15)$ & & $9(7-14)$ & & $9(7-21)$ & \\
\hline Discharged to rehab facility & 178 & 67.9 & 158 & 70.9 & 20 & 51.3 \\
\hline \multicolumn{7}{|l|}{ Postoperative complications } \\
\hline Atrial fibrillation & 125 & 47.7 & 107 & 48.0 & 18 & 46.2 \\
\hline Pneumonia & 72 & 27.5 & 52 & 23.3 & 20 & 51.3 \\
\hline Reoperation for bleeding & 20 & 7.6 & 13 & 5.8 & 7 & 17.9 \\
\hline Renal failure & 19 & 7.3 & 11 & 4.9 & 8 & 20.5 \\
\hline CVA & 15 & 5.7 & 10 & 4.5 & 5 & 12.8 \\
\hline Early mortality & 29 & 11.1 & 16 & 7.2 & 13 & 33.3 \\
\hline 5-y Survival & 132 & 50.4 & 118 & 52.9 & 14 & 35.9 \\
\hline Survival, y (median, 25th-75th percentile) & $5.2(1.7-9.8)$ & & $5.6(2.5-9.9)$ & & $0.6(0.2-7.8)$ & \\
\hline
\end{tabular}

$I C U$, Intensive care unit; $L O S$, length of stay; $C V A$, cerebrovascular accident.

demonstrates the survival curves by procedure type. Patients who underwent CABG only had the highest long-term survival. Patients who underwent aortic procedures had the highest early mortality; however, 10 -year survival is similar to that seen in patients who underwent valve surgery.

\section{Predictors of Mortality}

Risk factors from the Cox regression for early and late mortality are presented in Table 3 . For early mortality, significant risk factors were age, emergent status, aortic surgery, reoperative surgery, prolonged bypass time, and any major postoperative complication except for atrial fibrillation. Major postoperative complications included new-onset renal failure, pneumonia postoperative MI, CVA, and reop-

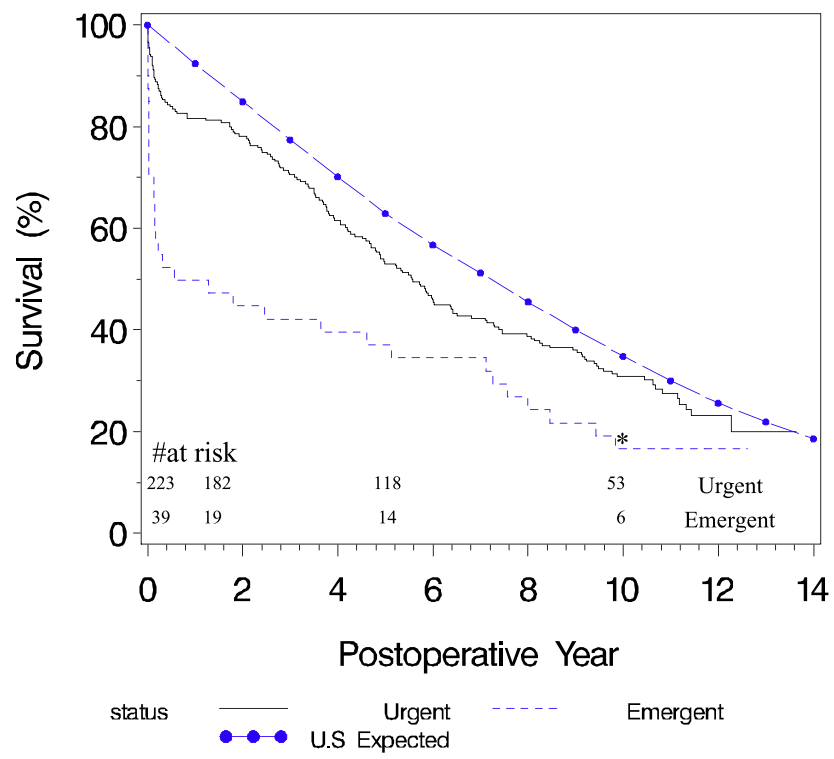

FIGURE 1. Kaplan-Meier survival analysis. eration for bleeding. New-onset renal failure was the greatest risk factor for early mortality, with a hazard ratio of 11 . Of the 19 patients with new-onset postoperative renal failure, 4 required hemodialysis. All 4 of these patients had early mortality, suggesting that requirement for hemodialysis significantly increases risk for early mortality. For late mortality, significant risk factors were concomitant peripheral vascular disease, emergent surgery, prolonged bypass time, and new-onset postoperative renal failure. Postoperative MI, CVA, pneumonia, and reoperation for bleeding did not increase the risk for late mortality. Increased body mass index decreased the risk for late mortality. Figure E2 demonstrates receiver operating curves for the existing clinical predictors for morality: the logistic EuroSCORE- and STS-predicted 30-day mortality. There was no difference between the AUROCs of the logistic EuroSCORE and STS $(0.745$ vs $0.694, P=.21)$.

\section{Quality of Life}

At the time of follow-up in 2005, we identified 84 survivors, of whom $62 \%$ returned SF-12 QoL surveys. All respondents were at least 5 years postoperatively from their cardiac surgery, with a 7-year median follow-up time. Figure 2 shows the QoL scores in the respondents in comparison with normative data from subjects older than 75 years, and subjects with heart disease. Across all variables of the SF-12, our respondents had scores comparable with those of these US cohorts. There was no difference in mental and physical combined scores between surgical patients, patients with heart disease, and general elderly patients. There was also no difference between QoL in survivors of urgent and emergent cardiac surgery. Table E2 lists the physical and mental combined scores of respondents after emergent cardiac surgery. The scores are comparable with the mean values for the elderly population. 
TABLE 3. Risk factors for early and late mortality

\begin{tabular}{|c|c|c|c|}
\hline Risk factor & Hazard ratio & Confidence interval & $P$ value \\
\hline \multicolumn{4}{|l|}{ Early mortality } \\
\hline \multicolumn{4}{|l|}{ Preoperative factors } \\
\hline Age & 1.163 & $1.028-1.315$ & .016 \\
\hline Female sex & 1.118 & $0.517-2.421$ & .776 \\
\hline HTN & 0.890 & $0.374-2.116$ & .792 \\
\hline Diabetes & 0.587 & $0.215-1.608$ & .300 \\
\hline NHYA class III or IV & 1.595 & $0.058-3.542$ & .249 \\
\hline Renal failure & 1.676 & $0.574-4.894$ & .345 \\
\hline COPD & 0.970 & $0.317-2.966$ & .957 \\
\hline PVD & 1.592 & $0.662-3.825$ & .299 \\
\hline CVA & 1.171 & $0.380-3.615$ & .783 \\
\hline BMI & 0.935 & $0.843-1.037$ & .219 \\
\hline Reoperation & 2.771 & $1.072-7.162$ & .035 \\
\hline Previous MI & 1.885 & $0.810-4.245$ & .144 \\
\hline Emergent surgery & 6.469 & $2.799-14.951$ & .001 \\
\hline Aortic surgery & 10.159 & $3.522-29.301$ & .001 \\
\hline Valve surgery & 1.693 & $0.672-4.269$ & .264 \\
\hline \multicolumn{4}{|l|}{ Postoperative factors } \\
\hline Bypass time (min) & 1.009 & $1.003-1.014$ & .003 \\
\hline Postoperative AF & 0.540 & $0.214-1.211$ & .135 \\
\hline MI & 9.500 & $2.567-35.174$ & .001 \\
\hline New renal failure & 11.161 & $3.933-31.669$ & .001 \\
\hline CVA & 6.493 & $2.121-19.871$ & .001 \\
\hline Pneumonia & 5.424 & $2.414-12.187$ & .001 \\
\hline Reoperation for bleeding & 4.081 & $1.430-11.643$ & .014 \\
\hline \multicolumn{4}{|l|}{ Late mortality } \\
\hline PVD & 1.865 & $1.26-2.77$ & .002 \\
\hline BMI & 0.96 & $0.92-1.00$ & .035 \\
\hline Emergent surgery & 1.51 & $1.01-2.27$ & .044 \\
\hline Bypass time (min) & 1.006 & $1.00-1.01$ & .001 \\
\hline New renal failure & 3.452 & $1.85-6.45$ & $<.0001$ \\
\hline
\end{tabular}

HTN, Hypertension; $N Y H A$, New York Heart Association; COPD, chronic obstructive pulmonary disease; $P V D$, peripheral vascular disease; $C V A$, cerebrovascular accident; $B M I$, body mass index; $M I$, myocardial infarction; $A F$, atrial fibrillation.

\section{DISCUSSION}

The principle finding of this study is that urgent and emergent cardiac surgery can be performed in octogenarian and nonagenarian patients with acceptable operative mortality,

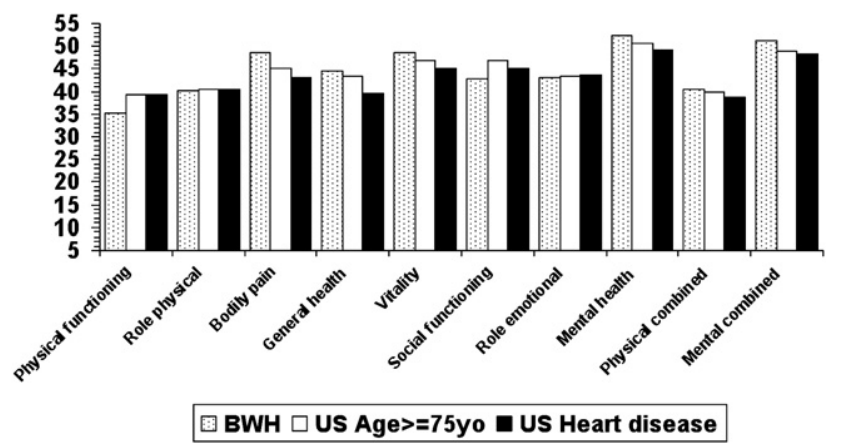

FIGURE 2. Postoperative quality-of-life scores compared with the US population and patients with heart disease, as assessed by the Medical Outcomes Study Short Form 12. ${ }^{14}$ long-term survival, and postoperative QoL. In our series 10-year survival and postoperative $\mathrm{QoL}$ were equivalent to those of the general elderly population in the United States. Despite nonelective cardiac surgery being associated with 2 to 3 times greater risk in the elderly, our operative mortality rate of $11 \%$ is similar to all inclusive operative mortality rates in previous studies of octogenarian patients, where mortality ranged from $9 \%$ to $20 \%{ }^{4,10}$ The patients in this study presented with unstable angina, evolving acute MI, valve dysfunction and congestive heart failure, shock, aortic aneurysm rupture, or acute aortic dissection. Although there are no randomized trials comparing medical management with nonintervention in these patients, the expected mortality would be high. Without surgical intervention, we believe many of these patients would likely have not survived their hospital stay. In our study, despite poor cardiac status at presentation, patients lived as long as the general population. Stoica and colleagues ${ }^{10}$ found that octogenarians who undergo elective cardiac surgery actually outlived their peers in the United Kingdom.

As expected, operative mortality was much higher with emergent operations compared with that seen after urgent operations, particularly for aortic surgery. Patients who presented for emergent surgery had an operative mortality of $33 \%$, nearly 5 times higher than the $7 \%$ operative mortality for those presenting for urgent operations. In octogenarian and nonagenarian patients who present with acute aortic dissection, clinical decisions regarding surgical intervention should consider this high mortality rate. For these patients, less invasive options, such as medical management or endovascular stent grafting, might be more appropriate. ${ }^{21}$

Like mortality, postoperative QoL is an important measure of success, particularly in this elderly population. We evaluated QoL at least 5 years postoperatively by using the well-established SF-12 assessment and compared responses with those of the general US elderly population and patients with cardiac disease. ${ }^{14,15}$ Postoperative patients had equivalent physical health and mental health scores. Thus patients after nonelective cardiac surgery can return to a normal physical and mental functional capacity. Even in patients who have emergent operations, excellent return of function can be achieved (Table E2). Huber and associates $^{22}$ also recently found that QoL improved in octogenarians 2 years after cardiac surgery.

Preoperative risk stratification in this group of patients is critical to guide clinical decision making. The AUROC is a well-established measure of diagnostic performance of a test. The AUROC can distinguish between nonpredictive (AUROC $<0.5$ ), less predictive (AUROC between 0.5 and 0.7 ), moderately predictive (AUROC between 0.7 and 0.9 ), and highly predictive (AUROC $>0.9$ ) tests. ${ }^{23,24}$ In this series the AUROC was 0.745 for the logistic EuroSCORE-predicted and 0.694 for the STS-predicted early mortality, with no statistically significant difference between 
the 2 . Thus both tests are only less to moderately predictive of true operative risk in this patient population. Previous studies have also found that these existing risk models might be limited in high-risk subgroups. ${ }^{19,25,26}$ New models need to be developed to appropriately risk stratify elderly patients undergoing cardiac surgery.

In our study we found that age, emergent surgery, aortic or reoperative cardiac surgery, prolonged bypass time, and virtually any significant postoperative complication, with the exception of atrial fibrillation, increased the risk for early mortality. Although preoperative comorbidities, such as renal failure, diabetes, and chronic obstructive pulmonary disease, likely contribute to early mortality, they were so prevalent in our patient population that they could not be used as a useful predictor. These results are similar to those of prior large population series in octogenarians in which medical comorbidities were found to be less predictive in comparison with younger age groups. ${ }^{4,10}$ Given this high-risk patient population, it is not surprising that postoperative complications are poorly tolerated. Zingone and coworkers ${ }^{27}$ also recently found that having a single postoperative complication doubled the risk for hospital death in 355 octogenarians after cardiac surgery. Thus to maximize outcomes in this patient population, good surgical technique must be combined with meticulous postoperative management. Preventative measures to minimize ventilator-associated pneumonias, such as early extubation, head of bed elevation, and aspiration precautions, should be emphasized. ${ }^{28}$ In addition, nephrotoxic drugs should be minimized, and renal function should be closely monitored. Of the major postoperative complications, only new-onset renal failure was predictive of late mortality, further emphasizing the importance of renal protection. Because body mass index was found to reduce the risk for late mortality, the importance of nutrition should also be emphasized.

\section{Limitations}

As a single-institution retrospective study, our study has several limitations. Our sample size is small and selective, which might limit translation to the general population. The sample size also likely decreases our ability to identify some significant risk factors that can influence overall outcome. The heterogeneity of surgical interventions precluded statistical analyses by operation type. Because our study evaluated outcomes after operations from 1994 to 1995, improvements in operative technique and perioperative management might have led to further improvements in operative mortality and postoperative complications than those presented in this study. In addition, our QoL assessment included a small, self-selected group of survivors. Poorly functioning survivors might not have returned the questionnaire. A responder bias analysis, however, did not reveal any significant differences in preoperative characteristics or in-hospital outcomes between responders and nonresponders. However, true postoperative QoL might be lower than reported. These limitations should be carefully considered when interpreting our results.

\section{CONCLUSION}

Nonelective cardiac surgery can be performed in octogenarian and nonagenarian patients with acceptable mortality and long-term survival. Emergent aortic surgery has the highest rate of operative mortality. Long-term postoperative QoL equals that of the general population. Medical comorbidities and existing clinical algorithms are not predictive of early mortality and should be carefully considered before they are used as contraindications for surgical intervention. Postoperative complications were stronger risk factors for operative deaths, and efforts to minimize complications, especially renal failure, should be maximized.

\section{References}

1. Day JC. Population projections of the United States by age, sex, race, and Hispanic origin: 1996 to 2050, U.S. Bureau of the Census, current population reports, P25-1130. Washington, DC: U.S. Bureau of the Census; 1996.

2. United Nations, Department of Economic and Social Affairs, Population Division. Population challenges and development goals. New York, NY: United Nations; 2005.

3. Association AH. Heart disease and stroke statistics-2008 update. Dallas, Texas: American Heart Association; 2008.

4. Alexander KP, Anstrom KJ, Muhlbaier LH, Grosswald RD, Smith PK, Jones RH, et al. Outcomes of cardiac surgery in patients $>$ or $=80$ years: results from the National Cardiovascular Network. J Am Coll Cardiol. 2000;35:731-8.

5. Rosengart TK, Finnin EB, Kim DY, Samy SA, Tanhehco Y, Ko W, et al. Open heart surgery in the elderly: results from a consecutive series of 100 patients aged 85 years or older. Am J Med. 2002;112:143-7.

6. Edmunds LH Jr, Stephenson LW, Edie RN, Ratcliffe MB. Open-heart surgery in octogenarians. N Engl J Med. 1988;319:131-6.

7. Varadarajan P, Kapoor N, Bansal RC, Pai RG. Clinical profile and natural history of 453 nonsurgically managed patients with severe aortic stenosis. Ann Thorac Surg. 2006;82:2111-5

8. Mirabel M, Iung B, Baron G, Messika-Zeitoun D, Detaint D, Vanoverschelde JL, et al. What are the characteristics of patients with severe, symptomatic, mitral regurgitation who are denied surgery? Eur Heart J. 2007;28:1358-65.

9. Bach DS, Radeva JI, Birnbaum HG, Fournier AA, Tuttle EG. Prevalence, referral patterns, testing, and surgery in aortic valve disease: leaving women and elderly patients behind? J Heart Valve Dis. 2007; 16:362-9.

10. Stoica SC, Cafferty F, Kitcat J, Baskett RJ, Goddard M, Sharples LD, et al. Octogenarians undergoing cardiac surgery outlive their peers: a case for early referral. Heart. 2006;92:503-6.

11. Barnett SD, Halpin LS, Speir AM, Albus RA, Akl BF, Massimiano PS, et al. Postoperative complications among octogenarians after cardiovascular surgery. Ann Thorac Surg. 2003;76:726-31.

12. Peterson ED, Cowper PA, Jollis JG, Bebchuk JD, DeLong ER, Muhlbaier LH, et al. Outcomes of coronary artery bypass graft surgery in 24,461 patients aged 80 years or older. Circulation. 1995;92(suppl):II85-91.

13. Ullery BW, Peterson JC, Milla F, Wells MT, Briggs W, Girardi LN, et al. Cardiac surgery in select nonagenarians: should we or shouldn't we? Ann Thorac Surg. 2008;85:854-60.

14. Ware J, Kosinski M, Turner-Bowker D, Gandek B. How to score version 2 of the SF-12 Health Survey. Lincoln, RI: QualityMetric Inc; 2005.

15. Xie J, Wu EQ, Zheng ZJ, Sullivan PW, Zhan L, Labarthe DR. Patient-reported health status in coronary heart disease in the United States: age, sex, racial, and ethnic differences. Circulation. 2008;118:491-7.

16. Kaplan E, Meier P. Nonparametric estimation from incomplete observations. J Am Stat Assoc. 1958;53:457-81.

17. Aries E. National vital statistics reports: National Center for Health Statistics. Atlanta, Ga: Centers for Disease Control and Prevention; 2007.

18. Shroyer AL, Coombs LP, Peterson ED, Eiken MC, DeLong ER, Chen A, et al. The Society of Thoracic Surgeons: 30-day operative mortality and morbidity risk models. Ann Thorac Surg. 2003;75:1856-65. 
19. Michel P, Roques F, Nashef SA. Logistic or additive EuroSCORE for high-risk patients? Eur J Cardiothorac Surg. 2003;23:684-7.

20. Hanley JA, McNeil BJ. The meaning and use of the area under a receiver operating characteristic (ROC) curve. Radiology. 1982;143:29-36.

21. Kpodonu J, Preventza O, Ramaiah VG, Shennib H, Wheatley GH 3rd, RodriquezLopez JA, et al. Endovascular repair of the thoracic aorta in octogenarians. Eur J Cardiothorac Surg. 2008;34:630-4.

22. Huber CH, Goeber V, Berdat P, Carrel T, Eckstein F. Benefits of cardiac surgery in octogenarians-a postoperative quality of life assessment. Eur J Cardiothorac Surg. 2007;31:1099-105.

23. Zweig MH, Campbell G. Receiver-operating characteristic (ROC) plots: a fundamental evaluation tool in clinical medicine. Clin Chem. 1993;39:561-77.
24. Greiner M, Pfeiffer D, Smith RD. Principles and practical application of the receiveroperating characteristic analysis for diagnostic tests. Prev Vet Med. 2000;45:23-41

25. Dewey TM, Brown DL, Das TS, Ryan WH, Fowler JE, Hoffman SD, et al. Highrisk patients referred for transcatheter aortic valve implantation: management and outcomes. Ann Thorac Surg. 2008;86:1450-7.

26. Nilsson J, Algotsson L, Hoglund P, Luhrs C, Brandt J. Early mortality in coronary bypass surgery: the EuroSCORE versus the Society of Thoracic Surgeons risk algorithm. Ann Thorac Surg. 2004;77:1235-40.

27. Zingone B, Gatti G, Rauber E, Tiziani P, Dreas L, Pappalardo A, et al. Early and late outcomes of cardiac surgery in octogenarians. Ann Thorac Surg. 2009;87:71-8.

28. Pieracci FM, Barie PS. Strategies in the prevention and management of ventilatorassociated pneumonia. Am Surg. 2007;73:419-32. 


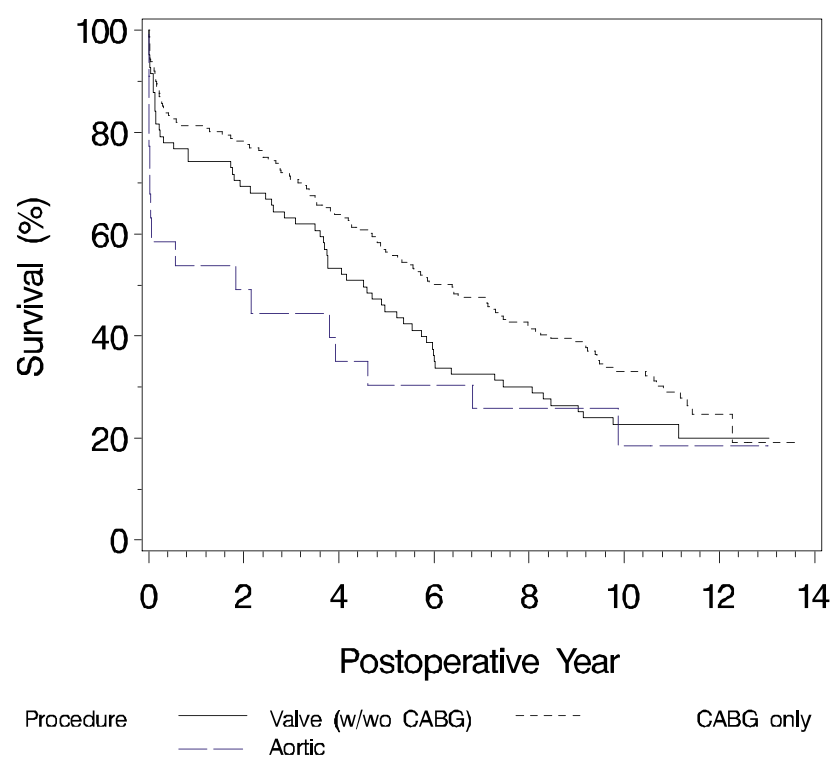

FIGURE E1. Kaplan-Meier survival analysis by procedure type. $C A B G$, Coronary artery bypass grafting.

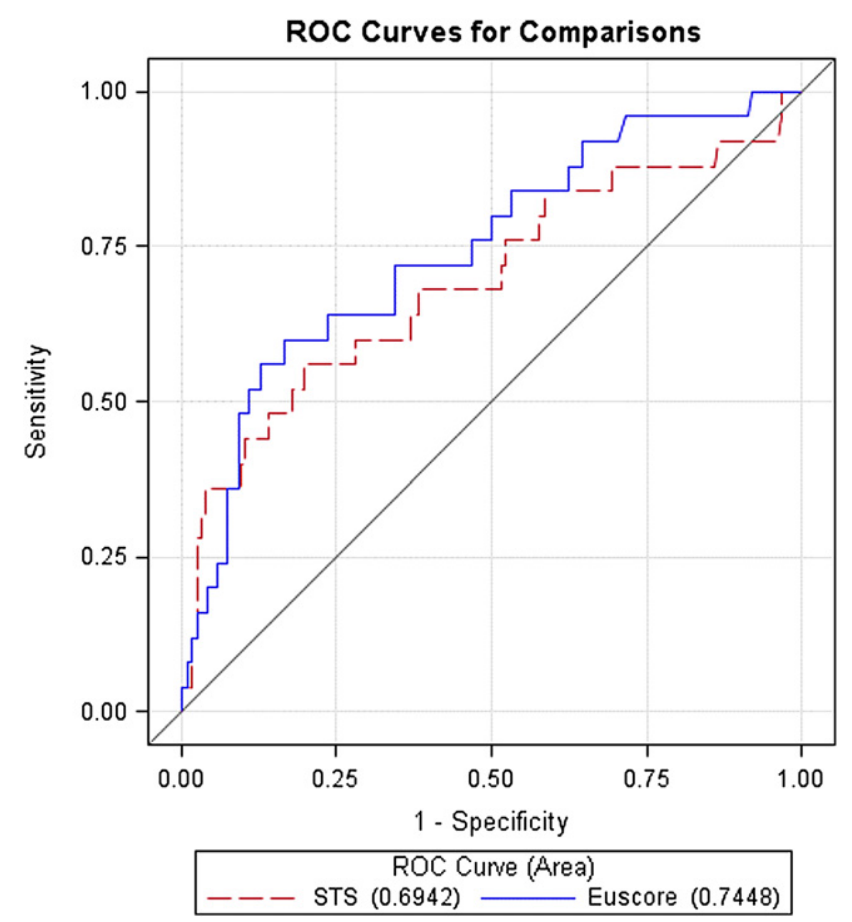

FIGURE E2. Receiver operating curves of EuroSCORE and Society of Thoracic Surgeons predictive algorithms.

TABLE E1. Operative mortalities and cause of death for emergent operations

\begin{tabular}{lclll}
\hline Age $(\mathbf{y})$ & Mortality POD & \multicolumn{1}{c}{ Indication } & \multicolumn{1}{c}{ Type of operation } & \multicolumn{1}{c}{ Cause of death } \\
\hline 80 & 0 & Aortic dissection & Descending aortic dissection repair/CABG & Recurrent dissection/cardiac arrest \\
90 & 0 & Aortic dissection & Ascending aortic replacement/AVR/CABG & Cardiac arrest \\
80 & 2 & Ruptured aneurysm & Thoracoabdominal aneurysm repair & CVA \\
92 & 3 & Aortic dissection & Ascending aortic replacement/CABG & Cardiac arrest \\
83 & 4 & Evolving MI & MVP/CABG & MSOF \\
89 & 6 & Ruptured aneurysm & Aortic arch replacement & CVA \\
84 & 7 & Evolving MI & CABG & Respiratory failure \\
89 & 7 & Angiographic accident & AVR/CABG & Ischemic bowel, CVA \\
90 & 7 & Shock/MI & CABG & Cardiogenic shock \\
84 & 7 & Shock/MI & CABG & Respiratory failure \\
82 & 8 & Evolving MI & CABG & MSOF, CVA \\
88 & 111 & Valve dysfunction/CHF & AVR/CABG & GI bleed, MSOF \\
\hline
\end{tabular}

$P O D$, Postoperative day; $C A B G$, coronary artery bypass grafting; $A V R$, aortic valve replacement; $C V A$, cerebrovascular accident; $M I$, myocardial infarction; $M V P$, mitral valve repair; $M S O F$, multisystem organ failure; $C H F$, congestive heart failure; $G I$, gastrointestinal.

TABLE E2. Postoperative quality of life among survivors after emergent operations

\begin{tabular}{llccc}
\hline \multicolumn{1}{c}{ Age (y) } & $\begin{array}{c}\text { Type of } \\
\text { operation }\end{array}$ & Follow-up (y) & PCS & MCS \\
\hline 86 & CABG & 8.5 & 34.2 & 35.5 \\
82 & CABG & 9.3 & 37.6 & 39.3 \\
85 & CABG & 8.0 & 37.6 & 21.8 \\
80 & CABG & 7.6 & 40.9 & 58.6 \\
80 & CABG & 6.8 & 41.5 & 41.2 \\
80 & CABG & 8.0 & 50.7 & 54.2 \\
86 & CABG & 6.6 & 54.2 & 58.7 \\
Mean & & & 42.4 & 44.2 \\
National average $\geq 75$ y & & & $39.5^{*}$ & $50.9 *$ \\
\hline$P C S$, Physical Combined Score from the Medical Outcomes Study Short Form 12; \\
$M C S$, Mental Combined Score from the Medical Outcomes Study Short Form 12; \\
$C A B G$, coronary artery bypass grafting. *No statistically significant difference.
\end{tabular}

